\title{
A predictive approach to the antioxidant capacity assessment of green and black tea infusions
}

\author{
Małgorzata Muzolf-Panek ${ }^{1}$ • $\cdot$ Anna Kaczmarek ${ }^{1} \cdot$ Anna Gliszczyńska-Świgło $^{2}$
}

Received: 18 May 2020 / Accepted: 26 October 2020 / Published online: 13 November 2020

(c) The Author(s) 2020

\begin{abstract}
Contemporary consumers drink significant amounts of tea because of its health-benefits mainly associated to the presence of polyphenols with high antioxidant activity. Therefore, the information how to obtain tea infusion of the highest quality, i.e. with high antioxidant capacity is needed. In this study, the various models for the prediction of total polyphenols and antioxidant activity of green and black tea infusions were developed and compared. Three mathematical equations: Spiro's, Peleg's and logarithmic, and two data mining techniques: multivariate adaptive regression splines (MARS) and artificial neural networks (ANNs) were used to build the predictive models. The results obtained show that Spiro's model could be used for the prediction of green tea quality expressed as total phenolic content or the antioxidant activity (determination coefficients above 0.99), whereas Peleg's model is more suitable for black tea quality prediction (determination coefficients above 0.99). Data mining techniques (MARS and ANNs) enable to create models fast and of simple application with very good acceptability (determination coefficients above 0.99 ).
\end{abstract}

Keywords Green tea $\cdot$ Black tea $\cdot$ Total polyphenol content $\cdot$ Antioxidant activity $\cdot$ Quality prediction models $\cdot$ Data mining techniques

\section{Introduction}

Tea has been under scientific attention for many years, because, as one of the most commonly consumed beverages worldwide, it provides significant amount of bioactive compounds in human diet. Tea is produced from the leaves of Camellia sinensis and is usually classified into three types: unfermented, semi-fermented and fermented tea based on the extent of fermentation. Green tea as non-fermented tea is obtained by an inactivation of the enzymes (polyphenol oxidase and peroxidase) in the fresh tea leaves either by roasting

Małgorzata Muzolf-Panek

malgorzata.muzolf-panek@up.poznan.pl

Anna Kaczmarek

anna.kaczmarek@up.poznan.pl

Anna Gliszczyńska-Świgło

anna.gliszczynska-swiglo@ue.poznan.pl

1 Department of Food Quality and Safety Management, Faculty of Food Science and Nutrition, Poznań University of Life Sciences, Poznań, 31, 60-624, Poland

2 Institute of Quality Science, Poznań University of Economics and Business, Poznań, Poland or steaming tea shoots. Thus, it contains a great number of polyphenolic compounds, mainly catechins, and alkaloids, including caffeine. Catechins account for about $30 \%$ of the dry weight of green tea leaves and most of the health benefits of green tea is referred to the high antioxidant activity of these flavonoids [1]. The fermentation of tea leaves induces enzymatic oxidation of tea catechins and their condensation to theaflavins and further polymerization of the latter to thearubigins. Both groups of compounds (theaflavins and thearubigins) are responsible for typical colour and strong, astringent flavour of black tea.

The antioxidant activity and polyphenol content of tea infusion are well documented and strong correlation between the two parameters has been observed [2]. Since the content of polyphenols has been used as the quality factor of many food products such as fruits and vegetables, also the quality of tea infusion could be expressed as phenolic content or the antioxidant activity. Green tea infusion is typically prepared by brewing tea leaves in hot water of $80^{\circ} \mathrm{C}$ for $3-5 \min$ [3], whereas black tea at $100{ }^{\circ} \mathrm{C}$ during 6-8 min [4]. Higher temperatures and prolonged time of extraction lowered the catechin (epi-form) content [3] which is not necessarily correlated with the decreasing antioxidant activity. At high 
temperature non-epi forms of catechins possessing high antioxidant activities could be formed [1,5]. Although scientific research does not provide unequivocal evidence of therapeutic effects of edible plants, some of them, such as tea, are used to prevent or support the treatment of certain diseases. Because some consumers drink significant amounts of tea to maintain or improve their health, the information how to obtain tea infusion of the highest quality i.e. with high antioxidant capacity is needed. It was previously shown that factors such as temperature and time of infusion, leaf size or quality of water influence the extraction process of bioactive compounds and their antioxidant properties, but as far as is known the predictive approach to tea infusion quality had been not previously discussed.

Kinetic modelling for tea was used to describe extraction of total phenolics, individual polyphenols and caffeine [6-8]. The modeling techniques were also applied in food science for an objective, fast and economic monitoring of the food quality changes under various conditions [9].

Kinetic models could be divided into two categories: physical and empirical ones. Physical models are based on the physical phenomena of mass transfer through plant particles and from external solid surfaces into bulk of the liquid phase [10]. The empirical ones do not describe any physical phenomena and include rather limited information, if any, on the fundamental principles involved in the extraction process. Nevertheless, the empirical models are used as an excellent tool for curve fitting and allow presentation in a function of physical properties and process conditions of both, the extraction medium and the extracting plant material.

The typical mathematical models include Spiro's steady state model-pseudo-first order model [8, 11-13], Peleg's model [14-16], Page's model [14], second-order model and logarithmic model $[14,15]$. For the investigation of the temperature influence on the extraction rate constant, the Arrhenius law is often implemented [8, 17-19].

Recently, an attempt based on data mining techniques application for the quality modeling of various products has been undertaken. Among these techniques, multivariate adaptive regression splines (MARS) and artificial neural networks (ANNs) have gained more attention. MARS is a nonparametric regression procedure that constructs the relation between the dependent and independent variables from a set of coefficients and basis functions that are entirely "driven" from the regression data [20,21]. This means that the model does not previously assume any functional relationship between the variables [20]. ANNs is an alternative approach to MARS techniques implemented in the finding of predictive models. They were applied in a wide range of problem domains since they could applicate very complex functions (linear and non-linear regressions) [22]. Moreover, these techniques do not need the explicit expression of physical meaning of the system/process under study, since the networks learn throughout successive trainings and the knowledge on how it works is not needed to perform the analysis thus ANNs are often ascribed to the "black-box" models [20, 22].

The aim of the study was to develop and compare the predictive models of tea infusion quality by investigating total polyphenol content and the antioxidant activity of leaf black and green teas in the function of infusion time and temperature. To this end, Spiro's steady state, Peleg's and logarithmic models were used as classical mathematical models. The effect of temperature was introduced to the models by the Arrhenius equation. MARS and ANNs models were also constructed as data mining techniques. Determination coefficients $\left(R^{2}\right)$, adjusted determination coefficients $\left(\operatorname{adj} . R^{2}\right)$, correlation coefficients $(r)$, and/or root mean square errors (RMSE) were used to assess how the experimental data fit to each model. The extraction of bioactive compounds was studied at four temperatures, namely $60,70,90$ and $100{ }^{\circ} \mathrm{C}$ to build the predictive models. The samples extracted at $80{ }^{\circ} \mathrm{C}$ were used as controls, in order to verify the applied conditions and to validate models.

\section{Materials and methods}

\section{Chemicals}

2,2-diphenyl-1-picrylhydrazyl (DPPH), 6-hydroxy-2,5,7,8tetramethylchroman-2-carboxylic acid (Trolox-water-soluble vitamin E analogue), Folin-Ciocalteu's reagent were purchased from Sigma-Aldrich (Steinheim, Germany). Sodium carbonate was obtained from POCh (Gliwice, Poland). Methanol and n-hexane were purchased from ChemPur (Poland). Water was purified using the Milli-Q system (Millipore, Bedford, MA, USA).

\section{Tea samples and tea infusion preparation}

Green and black leaf teas were purchased in China and Poland, respectively. Green tea was Lv Mao Hou, grown in Zhang Yi Yuan (Yongtai, Fujian). The black tea was packaged by Poznańska Palarnia Kawy ASTRA in Poznań, and the dried tea leaves were from China's Yunnan province.

Tea infusions were prepared by brewing of $2 \mathrm{~g}$ of tea leaves with $100 \mathrm{ml}$ of purified water, at five different temperatures $\left(60,70,80,90\right.$ and $\left.100{ }^{\circ} \mathrm{C}\right)$ and at ten extraction times $(0.25,0.5,1,3,5,8,10,12,15,30$ and $60 \mathrm{~min})$. The initial time was set when the water was added to the tea leaves. The mixture was stirred during brewing using the magnetic stirrer (MS-H-Pro plus, Chemland, Poland) with electronic control for constant speed. When the time of extraction was reached the leaves were separated from the aqueous extract 
and the extract was cooled down to room temperature. The tea extract was then filtered twice through the filter (type 388 filter, Filtrak, Niederschlag Bärenstein, Germany). All samples were prepared in triplicate.

\section{Antioxidant activity}

The $\mathrm{DPPH}^{\bullet}$ free radical scavenging activity measurements were carried out according to the procedure of SánchezMoreno et al. [23] with some modifications [24]. The $\mathrm{DPPH}^{\bullet}$ radical scavenging activity expressed in the TEAC values (Trolox equivalent antioxidant capacity in mmol of Trolox per g of tea leaves) may reflect the concentration of antioxidants (AOX) as it was previously shown by Jurinjak Tušek et al. [10].

\section{Total polyphenol content}

Total polyphenol content (TPC) was determined using Folin-Ciocalteu's reagent (FCR) as described by Singleton and Rossi [25].The results were expressed as $\mathrm{mg}$ of gallic acid equivalents (GAE) per $\mathrm{g}$ of tea leaves.

\section{HPLC determination of bioactive compound content}

The composition and content of catechins and gallic acid in tea infusions were determined using a HPLC method developed by Enko and Gliszczyńska-Świgło [26].

\section{Mathematical models}

Analysis of the effects of infusion time and temperature was performed by fitting the experimental data of total polyphenol content and the antioxidant activity to kinetic models: Spiro's steady state [13], Peleg's [14, 16] and logarithmic [14] models. The Spiro's steady state model which predicts first order behavior is expressed by the equation (Eq. 1):

$d c / d t=k \times\left(C_{\infty}-C\right)$

The integrated equation is as follows (Eq. 2):

$\ln \left(C_{\infty} /\left(C_{\infty}-C\right)\right)=k \times t+a$

where $C_{\infty}$ is the concentration of TPC or AOX at equilibrium and $C$ is the concentration at any time, $k$ is the observed first order rate constant and $a$ is the intercept that is typically small but not predicted by the model.

Peleg's model was developed to describe the sorption isotherms of food materials [16] (Eq. 3):

$C(t)=C_{0}+t /\left(K_{1}+K_{2} \times t\right)$

where $C(t)$ is the concentration of bioactive compounds at time $t, K_{l}$ is Peleg's rate constant and $K_{2}$ is Peleg's capacity constant and $C_{0}$ is the concentration of bioactive compounds at time $t=0$. The model was adopted for description of solid-liquid extraction process [15] since the shape of the extraction curves of bioactive compounds from plant sources was very similar to the one of sorption curves. As initial concentration of TPC and AOX is zero, $C_{0}$ value equals zero and modified Peleg's model was fitted to the experimental data according the equation (Eq. 4):

$C(t)=t /\left(K_{1}+K_{2} \times t\right)$

The Peleg's rate constant $K_{l}$ relates to extraction rate $\left(R_{0}\right)$ at the very beginning of the extraction process thus at $t=t_{0}$ the Eq. (4) becomes Eq. (5):

$C(t=0)=R_{0}=1 / K_{1}$

The Peleg's capacity constant $K_{2}$ corresponds to maximum extraction yield that is equilibrium concentration $\left(C_{e}\right)$ of bioactive compounds thus at $t \rightarrow \infty$ the Eq. (4) becomes Eq. (6):

$C(t \rightarrow \infty)=C_{e}=1 / K_{2}$

Logarithmic model was used to the experimental data [14] following the equation (Eq. 7)

$C(t)=a \times \ln t+b$

where $a$ and $b$ are logarithmic model constants and $C(t)$ is the concentration of bioactive compounds at time $t$.

\section{Temperature effect}

Temperature dependence of the extraction kinetics could be assessed using Arrhenius equation (Eq. 8):

$k=k_{0} \times \exp \left(-E_{a} /(R \times T)\right)$

where $k$ represents the extraction rate, $k_{0}$ is pre-exponential factor, $E_{a}$ is the activation energy, $R$ is the universal gas constant and $T$ is the absolute temperature.

The modified logistic Arrhenius equation was given by the equation (Eq. 9):

$\ln k=\ln k_{0}-E_{a} /(R \times T)$

A plot of $\ln k$ versus $1 / T$ gives a regression line with the slope $-E_{a} / R$ and $\ln k_{0}$ as intercept. Arrhenius equation is also used for empirical models, but then the parameters $-E_{a} / R$ and $\ln k_{0}$ do not really have a physical meaning and the Eq. (8) is often presented as Arrhenius-like equation (Eq. 10):

$k=A \times \exp (-B / T)$

where A and B are the model parameters. 


\section{Multivariate adaptive regression splines (MARS)}

The main idea in MARS is its ability for dividing the whole space of each independent variable into various sub-regions (the joining points of these sub-regions are called knots and are derived from the data set) [20]. Then two-sided truncated spline functions are defined as basis functions for describing the relationships between the dependent and predictor variables in each distinct intervals of the predictor variable [20, 21]. The basis functions are as follows (Eqs. 11, 12):

$h(x-t)_{+}=\left\{\begin{array}{l}x-t, \text { if } x>t \\ 0 \text { otherwise }\end{array}\right.$

$h(t-x)_{+}=\left\{\begin{array}{l}t-x, \text { if } x<t \\ 0 \text { otherwise }\end{array}\right.$

where parameter $t$ is the knot of the basis functions and the $"+"$ signs next to the terms $(t-x)$ and $(x-t)$ indicate that only positive results of the respective equations are considered; otherwise the respective functions evaluate to zero [20].

For each of the predictor variables MARS selects the pair of splines and the knot location, that best describe the dependent variable. In a next step, the basis functions together with the model parameters (estimated via least squares estimation) are combined to build the general MARS model equation, described as (Eq. 13):

$y=f(x)=\beta_{0}+\sum_{m=1}^{M} \beta_{m} H_{m}(x)$

where $y$ is the predicted value for the dependent variable, $\beta_{0}$ is the intercept term and $\beta_{m}$ represents a regression coefficient that is estimated by minimizing the residual sum of squares, $M$ - the number of basis functions in the current model and $H_{m}(x)$ is the product of basis functions (Eq. 14) [20, 21]:

$H_{m}=\prod_{(k=1)}^{K} h\left(t_{k} ; x\right)$.

To avoid an excessive number of spline functions in the final MARS model (so-called overfitting) the generalized cross-validation $(G C V)$ error as an adjusted residual sum of squares (Eq. 15), in which a penalty for the model complexity (C) is incorporated (Eq. 16), is calculated

$G C V=\sum_{i=1}^{N}\left(y_{i}-f\left(x_{i}\right)\right)^{2} /\left(1-\frac{C}{N}\right)^{2}$

with

$C=1+c d$ where $N$ is the number of cases in the data set, $d$ is the effective degrees of freedom, which is equal to the number of independent basis functions $(M)$. The quantity $c$ is the penalty for adding a basis function. The value of $C$ increases with the number of basis functions in the model [20].

In this study, MARS models created for the data matrix included maximum 21 basis functions, two degrees of interaction. The penalty was set to 2 , and threshold to 0.0005 . Increased numbers of basis functions did not increase the values of $R^{2}$ or $a d j . R^{2}$ nor influence the value of $G C V$.

\section{Artificial neural networks (ANNs)}

The data set collected in this study has been divided into: learning (65\%), training (15\%) and validating (20\%) sets. Multilayer feed-forward fully connected ANN has been trained with the Broyden-Fletcher-Goldfarb-Shanno learning algorithm (200 epoch). The search for an appropriate ANN model was performed using multilayer perceptron (MLP) and radial basis function (RBF) networks. In total, 20 networks were tested of which the best five were retained. The network architecture created for the tea data matrix included an input layer, one hidden layer of neurons, and an output layer. The input layer consisted of two neurons, 3-9 neurons in the hidden layer for TPC values and 4-9 neurons for the TEAC values (depending on the ANN model), and one neurons in the output layer (TPC or the TEAC values). The sums of squares error function was used during the network training process. The success of the model to predict TPC and the TEAC values was evaluated based on the correlation coefficients for: training-a percentage of the samples in the learning set correctly predicted during the networks learning step; test-a percentage of the samples in the testing set correctly predicted during the networks testing step and validation-a percentage of the samples in the validation set (samples not used in the learning and testing steps) correctly predicted by the models during the networks validation step.

\section{Statistical analysis}

All analyses were run in triplicate. The statistical tests were performed using Statistica 13.0 software (Statsoft, Oklahoma, USA) at $\alpha=0.05$.

Values of kinetic parameters were estimated by non-linear estimation analysis using least-squares criterion with Levenberg-Marquardt algorithm. The goodness of fits of the models was assessed using determination coefficient $\left(R^{2}\right)$ (Eq. 17):

$R^{2}=1-($ total sum of squares $) /($ residual sum of squares $)$,

correlation coefficients $(r)$, root mean square error (RMSE) (Eq. 18): 
$R M S E=\sqrt{\sum_{i=1}^{n}\left(y_{i}-\hat{y}_{1}\right)^{2} / n}$

and coefficient of variation $(C V)$ (Eq. 19):

$C V=100 / \bar{y} \times \sqrt{\sum_{i=1}^{n}\left(y_{i}-\hat{y}_{1}\right)^{2} / n}$

and/or generalized cross-validation (GCV) error (Eq. 15). Analysis of variance (ANOVA) was performed to statistically evaluate all parameters obtained.

\section{Results and discussion}

\section{Bioactive compound content and the antioxidant activity of tea}

The changes in the TPC of green and black teas are shown in Fig. 1. The antioxidant activity of the infusions expressed in the TEAC values calculated from the DPPH radical scavenging assay is presented in Fig. 2. By analyzing the data obtained it could be concluded that TPC and the TEAC values of green and black teas were affected by the time and temperature of extraction $(\mathrm{p}<0.05)$. With the increasing temperature and time of brewing, the content of total polyphenols increased (Fig. 1a, b). After 60 min of brewing at $100{ }^{\circ} \mathrm{C}$ TPC values reached the highest level of $78.3 \mathrm{mg}$ $\mathrm{GAE} / \mathrm{g}$ for green tea and $55.6 \mathrm{mg} \mathrm{GAE} / \mathrm{g}$ for black tea.

It was found that also the composition of both teas varied (Tables 1 and 2). The green tea contained EGCG, EGC, ECG, and GC as the main catechins which accounted for about $90 \%$ of catechins (after $15 \mathrm{~min}$ of brewing at $100{ }^{\circ} \mathrm{C}$ ). The main catechins found in black tea prepared at $100{ }^{\circ} \mathrm{C}$ were as follows: EGC, EGCG and ECG which together constituted about $86 \%$ of catechins. These findings are in agreement with the results of Enko \& Gliszczyńska-Świgło [26], Muzolf et al. [27] and Gramza et al. [28]. However, the effect of time and temperature on the particular black and green tea components was different comparing to their TPC changes (Tables 1 and 2).

For green tea, the maximum levels of GC, GCG, ECG, ECGC and EGC were reached at $80{ }^{\circ} \mathrm{C}$ (Table 1). According to our results, there were no significant differences between EC content at various temperature, whereas, gallic acid (GA) content increased with temperature showing the maximum level at $100{ }^{\circ} \mathrm{C}$. It was observed in previous studies that extraction at $85{ }^{\circ} \mathrm{C}$ gave the highest contents of ECG and EGC, whereas for non-epistructured catechins the highest levels were reached at $95{ }^{\circ} \mathrm{C}$ [3]. The levels of GA and catechins, namely: EC, ECG, EGCG and GCG slightly increased
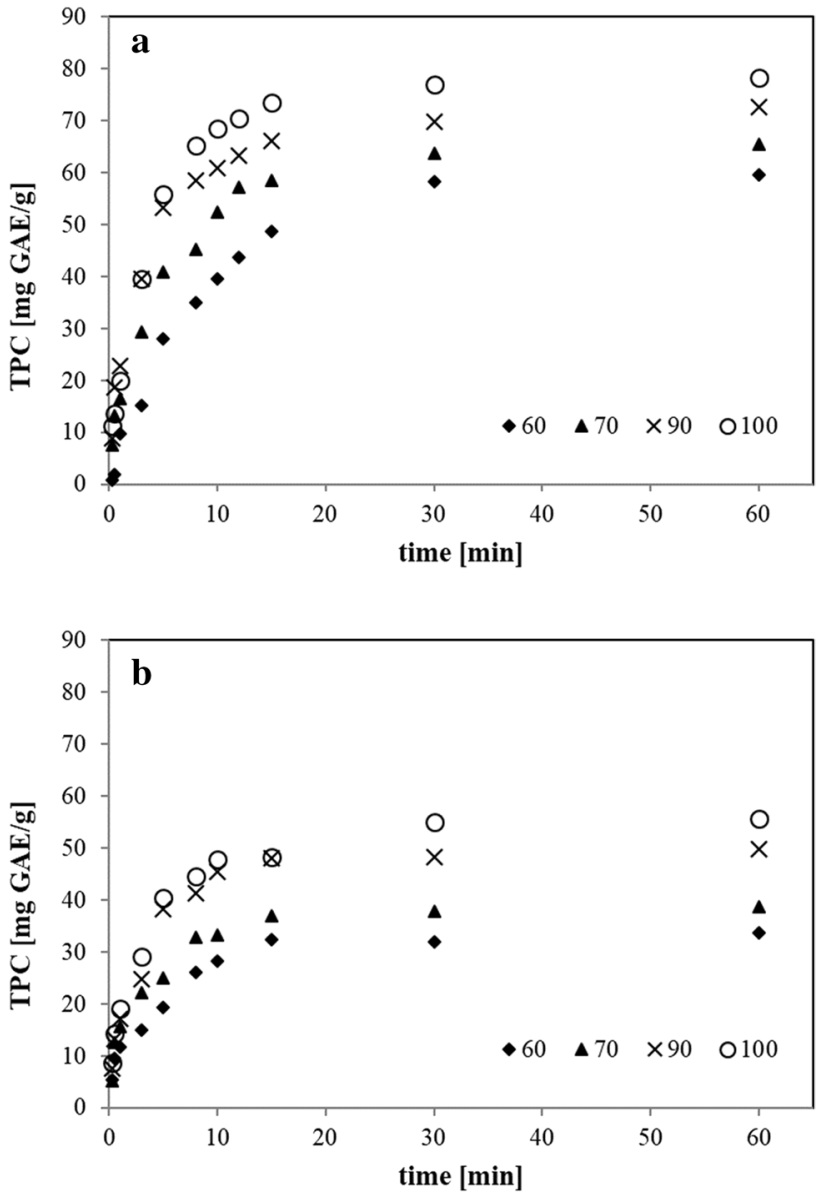

Fig. 1 Total polyphenol content (TPC) in green (a) and black (b) teas brewed at temperatures: $60,70,90,100{ }^{\circ} \mathrm{C}$

with increasing time of brewing at $70{ }^{\circ} \mathrm{C}$ (Table 2). EGC increased with time up to 10 min of brewing and, there was no trend observed in GC changes in green tea infusion with time.

For black tea, the contents of EGC and GCG increased with the increasing temperature (Table 1). EC showed the maximum level at $80{ }^{\circ} \mathrm{C}$, then further increase of temperature did not change the content of the compound. The levels of EGCG and ECG were stable between 60 and $70{ }^{\circ} \mathrm{C}$ and then increased up to $100{ }^{\circ} \mathrm{C}$. The effect of time on particular catechins in black tea was various (Table 2). The contents of EGCG, GCG and ECG increased at the beginning of brewing process (between 5 and $8 \mathrm{~min}$ ) and thereafter their levels were stable with time. There was observed a steady increase of EC and a decrease of GC with time. EGC increased, up to 8 min of extraction, and thereafter decreased.

A significant increase of the antioxidant activity of both teas with increasing temperature and time was also observed (Fig. 2a, b). The TEAC values increased after $60 \mathrm{~min}$ of brewing at $100{ }^{\circ} \mathrm{C}$ up to $706 \mathrm{mmol} / \mathrm{g}$ for green tea (Fig. 2a) and $577 \mathrm{mmol} / \mathrm{g}$ for black tea (Fig. 2b). Correlation 

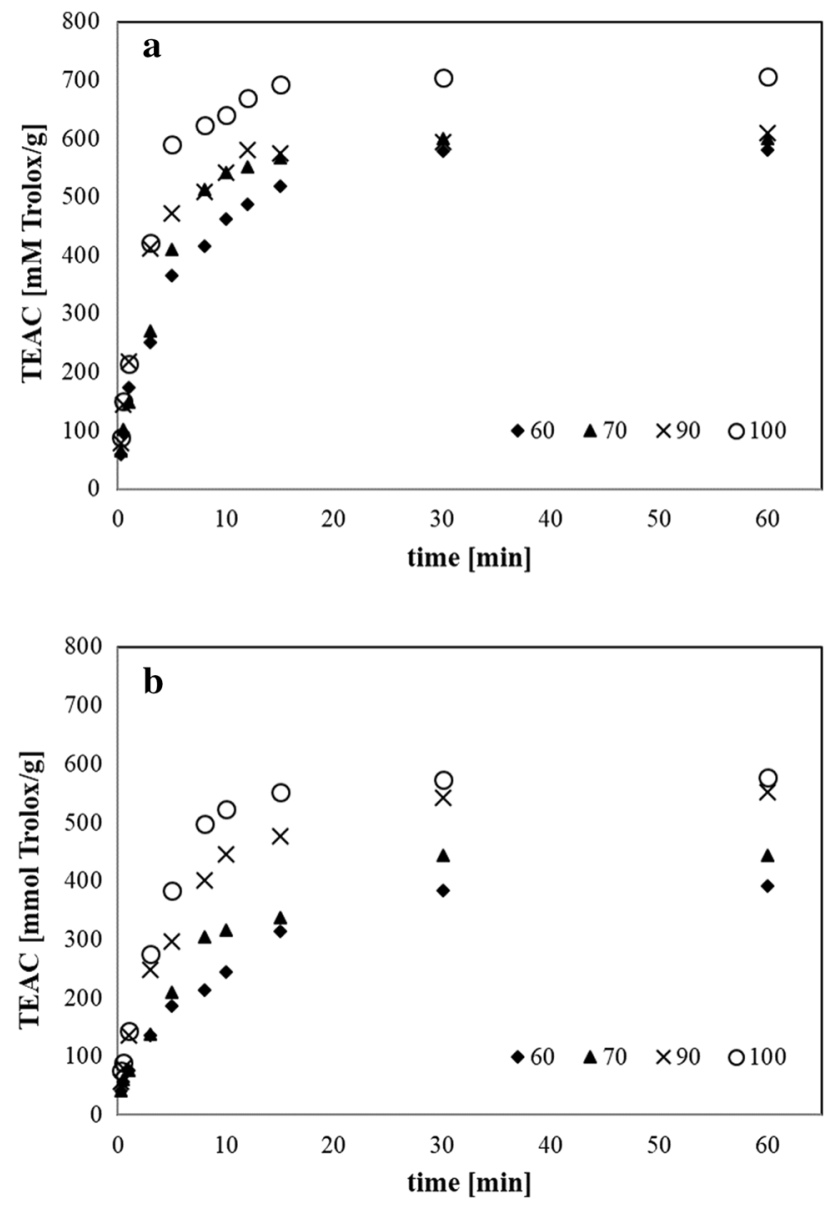

Fig. 2 The antioxidant activity expressed in the TEAC values of green (a) and black (b) teas brewed at temperatures: 60, 70, 90, $100{ }^{\circ} \mathrm{C}$

coefficient between TPC and the TEAC values is very high (0.98) for both teas. The effect of temperature and time on TPC and the antioxidant activity of teas was previously reported by others [4, 29-31]. Moreover, TPC and the antioxidant activity of black tea was significantly lower than in green tea at each temperature tested, which is in accordance with the previous studies [32].

\section{Development and evaluation of mathematical models for TPC and the antioxidant activity of tea}

The extraction curves for both types of teas, obtained by plotting TPC or the TEAC values vs time of brewing were similar in shape (Figs. 1 and 2). A rapid increase of TPC and the TEAC values at the very beginning of the process was observed followed by slow increase in the further stage of extraction until the equilibrium concentration of bioactive compounds was achieved. Similar results were previously observed for compounds extracted from tea $[8,11]$, sage
[33], Asteraceae plants [15], soybeans [14] or grape cane [34].

Based on the shape of the curves, Spiro's, Peleg's and logarithmic models were chosen for description of total polyphenol and the antioxidant activity changes in green and black teas and the predictive model development. Proposed models were fitted to the experimental data by non-linear regression. The $R^{2}$ and $R M S E$ values of each model were used for the assessment of model adequacies (Tables 3 and $4)$.

Based on the results, it could be concluded that all models had very high goodness of fit as representing by high $R^{2}$ and low RMSE values (Tables 3 and 4). Nevertheless, Peleg's model could best describe the extraction of polyphenols as well as the antioxidant activity changes for both types of tea with $R^{2}$ above 0.99 and similar, low $R M S E$ values.

For Spiro's model, the rate of polyphenol extraction $(k)$ significantly increased with increasing temperature of brewing (Table 3). This effect could be explained by disruption of the cell wall by high temperature which made phenolic compounds easier to extract from tea leaves [8]. Moreover, $k$ values for black tea were higher for about $37-48 \%$ than the corresponding $k$ values for green tea. This indicates that the extraction of phenolic compounds is faster from black tea than from green tea at each temperature tested which was previously observed by Jaganyi and Price [8] for caffeine extraction. The difference could be explained by the various manufacturing process of the tea [35]. During green tea processing cellular structure remains almost intact, while in the black tea process, the leaves are rolled, so that the leaf cells are broken and the content of the cell cytoplasm is released. This makes the black tea phenolic compounds more available to the extraction than green tea catechins.

For Peleg's model, $K_{l}$ constant (Table 3), related to the initial extraction rate $\left(R_{0}\right.$, calculated from Eq. (5)) of polyphenols, decreased with increasing temperature indicating that the extraction of polyphenols at the beginning of the process was accelerated with temperature $\left(R_{0}\right.$ from $0.137 \mathrm{mg} \mathrm{GAE} / \mathrm{g} / \mathrm{s}$ to $0.586 \mathrm{mg} \mathrm{GAE} / \mathrm{g} / \mathrm{s}$ for green tea, and from $0.207 \mathrm{mg} \mathrm{GAE} / \mathrm{g} / \mathrm{s}$ to $0.450 \mathrm{mg} \mathrm{GAE} / \mathrm{g} / \mathrm{s}$ for black tea). Although, at the temperatures of 60 and $70{ }^{\circ} \mathrm{C}$, the $R_{0}$ values were higher for black tea comparing to green tea, reverse order was observed at the temperatures of 90 and $100{ }^{\circ} \mathrm{C}$. This implies that, at higher temperatures, the extraction of polyphenols from green tea at the beginning of the process was faster compared to black tea. The effect could be partly explain by the significant increase of the extraction rate of some individual catechins (such as epigallocatechin gallate, gallocatechin gallate and catechin) in green tea infusion, at the temperature of 85 and $95{ }^{\circ} \mathrm{C}$ comparing to the extraction rate of these compounds at $75{ }^{\circ} \mathrm{C}$ [3]. The $K_{2}$ values calculated for TPC (Table 3) also decreased with higher temperature which indicated the temperature-dependent 
Table 1 The effect of temperature (after 15 min of brewing) on gallic acid (GA) and catechin contents in green and black tea

\begin{tabular}{|c|c|c|c|c|c|c|c|c|c|c|}
\hline COMPOUND & $60^{\circ} \mathrm{C}$ & & $70^{\circ} \mathrm{C}$ & & $80^{\circ} \mathrm{C}$ & & $90^{\circ} \mathrm{C}$ & & $100^{\circ} \mathrm{C}$ & \\
\hline \multicolumn{11}{|l|}{ Green tea } \\
\hline Gallic acid (GA) & $1.27^{\mathrm{a}}$ & \pm 0.10 & $1.50^{\mathrm{b}}$ & \pm 0.05 & $1.46^{\mathrm{b}}$ & \pm 0.03 & $1.52^{\mathrm{b}}$ & \pm 0.03 & $1.76^{\mathrm{c}}$ & \pm 0.13 \\
\hline Epicatechin (EC) & $17.13^{\mathrm{a}}$ & \pm 0.12 & $18.65^{\mathrm{a}}$ & \pm 1.17 & $18.22^{\mathrm{a}}$ & \pm 0.73 & $18.00^{\mathrm{a}}$ & \pm 0.56 & $17.08^{\mathrm{a}}$ & \pm 0.87 \\
\hline Epicatechin gallate (ECG) & $39.94^{\mathrm{c}}$ & \pm 0.40 & $43.59^{\mathrm{b}}$ & \pm 1.26 & $49.49^{\mathrm{a}}$ & \pm 2.35 & $47.44^{\mathrm{a}}$ & \pm 1.43 & $47.58^{\mathrm{a}}$ & \pm 2.50 \\
\hline Epigallocatechin (EGC) & $92.80^{\mathrm{c}}$ & \pm 1.41 & $99.09^{\mathrm{bc}}$ & \pm 0.81 & $113.20^{\mathrm{a}}$ & \pm 5.63 & $104.25^{\mathrm{b}}$ & \pm 2.82 & $100.50^{\mathrm{b}}$ & \pm 1.62 \\
\hline Epigallocatechin gallate (EGCG) & $104.77^{b}$ & \pm 5.47 & $111.81^{\mathrm{b}}$ & \pm 5.36 & $130.42^{\mathrm{a}}$ & \pm 5.23 & $125.75^{\mathrm{a}}$ & \pm 2.37 & $122.50^{\mathrm{a}}$ & \pm 4.08 \\
\hline Gallocatechin (GC) & $28.88^{c}$ & \pm 1.69 & $32.39^{\mathrm{ab}}$ & \pm 1.17 & $34.23^{\mathrm{a}}$ & \pm 1.25 & $32.06^{\mathrm{ab}}$ & \pm 1.79 & $30.25^{\mathrm{bc}}$ & \pm 1.48 \\
\hline Gallocatechin gallate (GCG) & $13.03^{\mathrm{c}}$ & \pm 0.85 & $13.69^{\mathrm{c}}$ & \pm 0.28 & $17.41^{\mathrm{a}}$ & \pm 1.12 & $16.67^{\mathrm{ab}}$ & \pm 0.20 & $15.59^{\mathrm{b}}$ & \pm 0.66 \\
\hline \multicolumn{11}{|l|}{ Black tea } \\
\hline Gallic acid (GA) & $8.04^{\mathrm{b}}$ & \pm 0.53 & $9.17^{\mathrm{a}}$ & \pm 0.28 & $7.75^{\mathrm{b}}$ & \pm 0.49 & $7.77^{\mathrm{b}}$ & \pm 0.98 & $7.06^{\mathrm{b}}$ & \pm 0.35 \\
\hline Epicatechin (EC) & $1.09^{\mathrm{b}}$ & \pm 0.15 & $1.32^{\mathrm{b}}$ & \pm 0.05 & $2.40^{\mathrm{a}}$ & \pm 0.17 & $2.39^{\mathrm{a}}$ & \pm 0.24 & $2.42^{\mathrm{a}}$ & \pm 0.03 \\
\hline Epicatechin gallate (ECG) & $15.77^{\mathrm{c}}$ & \pm 3.72 & $15.46^{\mathrm{c}}$ & \pm 0.77 & $20.00^{\mathrm{bc}}$ & \pm 0.63 & $22.79^{\mathrm{ab}}$ & \pm 2.67 & $26.40^{\mathrm{a}}$ & \pm 2.43 \\
\hline Epigallocatechin (EGC) & $39.80^{\mathrm{b}}$ & \pm 4.88 & $40.00^{\mathrm{b}}$ & \pm 1.85 & $44.29^{\mathrm{b}}$ & \pm 2.16 & $45.65^{\mathrm{ab}}$ & \pm 2.55 & $50.70^{\mathrm{a}}$ & \pm 4.29 \\
\hline Epigallocatechin gallate (EGCG) & $29.37^{b c}$ & \pm 4.96 & $28.16^{\mathrm{c}}$ & \pm 3.42 & $35.30^{\mathrm{ab}}$ & \pm 2.17 & $38.16^{\mathrm{a}}$ & \pm 4.15 & $40.62^{\mathrm{a}}$ & \pm 2.44 \\
\hline Gallocatechin (GC) & $9.76^{\mathrm{a}}$ & \pm 1.38 & $5.87^{\mathrm{b}}$ & \pm 0.23 & $6.05^{\mathrm{b}}$ & \pm 0.33 & $5.47^{\mathrm{b}}$ & \pm 0.71 & $5.02^{\mathrm{b}}$ & \pm 0.25 \\
\hline Gallocatechin gallate (GCG) & $0.47^{\mathrm{d}}$ & \pm 0.13 & $2.04^{c}$ & \pm 0.29 & $2.99^{\mathrm{b}}$ & \pm 0.09 & $3.38^{\mathrm{b}}$ & \pm 0.34 & $4.37^{\mathrm{a}}$ & \pm 0.27 \\
\hline
\end{tabular}

For each compound, the significant differences in the content of a compound with temperature were indicated by various superscript letters $(\mathrm{p}<0.05)$

Table 2 The effect of time $\left(\right.$ at $\left.70{ }^{\circ} \mathrm{C}\right)$ on gallic acid (GA) and catechin contents in green and black tea

\begin{tabular}{|c|c|c|c|c|c|c|c|c|c|c|}
\hline COMPOUND & $5 \mathrm{~min}$ & & $8 \min$ & & $10 \mathrm{~min}$ & & $15 \mathrm{~min}$ & & $30 \mathrm{~min}$ & \\
\hline \multicolumn{11}{|l|}{ Green tea } \\
\hline $\begin{array}{l}\text { Gallic acid (GA) } \\
\text { Gallic acid (GA) }\end{array}$ & $1.36^{\mathrm{b}}$ & \pm 0.11 & $1.38^{\mathrm{b}}$ & \pm 0.14 & $1.39^{\mathrm{b}}$ & \pm 0.10 & $1.50^{\mathrm{b}}$ & \pm 0.05 & $1.69^{\mathrm{a}}$ & \pm 0.04 \\
\hline Epicatechin (EC) & $15.83^{\mathrm{b}}$ & \pm 0.58 & $16.48^{b}$ & \pm 0.55 & $16.67^{\mathrm{b}}$ & \pm 1.37 & $18.65^{\mathrm{a}}$ & \pm 1.17 & $19.26^{\mathrm{a}}$ & \pm 0.47 \\
\hline Epicatechin gallate (ECG) & $34.41^{\mathrm{d}}$ & \pm 1.44 & $37.21^{\mathrm{c}}$ & \pm 0.87 & $40.04^{b}$ & \pm 1.99 & $43.59^{\mathrm{a}}$ & \pm 1.26 & $43.03^{\mathrm{a}}$ & \pm 1.29 \\
\hline Epigallocatechin (EGC) & $91.80^{\mathrm{c}}$ & \pm 2.12 & $94.22 \mathrm{bc}$ & \pm 3.79 & $100.41^{\mathrm{a}}$ & \pm 2.61 & $99.09^{\mathrm{ab}}$ & \pm 0.81 & $97.35^{a b c}$ & \pm 5.46 \\
\hline Epigallocatechin gallate (EGCG) & $89.64^{c}$ & \pm 4.81 & $102.47^{b}$ & \pm 3.17 & $98.23^{\mathrm{b}}$ & \pm 3.75 & $111.81^{\mathrm{a}}$ & \pm 5.36 & $111.34^{\mathrm{a}}$ & \pm 4.49 \\
\hline Gallocatechin (GC) & $28.70^{\mathrm{b}}$ & \pm 1.11 & $31.46^{\mathrm{a}}$ & \pm 0.66 & $27.46^{\mathrm{b}}$ & \pm 0.78 & $32.39^{\mathrm{a}}$ & \pm 1.69 & $30.64^{\mathrm{a}}$ & \pm 0.53 \\
\hline Gallocatechin gallate (GCG) & $12.13^{\mathrm{bc}}$ & \pm 0.6 & $12.86^{\mathrm{b}}$ & \pm 0.35 & $11.69^{\mathrm{c}}$ & \pm 0.34 & $13.69^{\mathrm{a}}$ & \pm 0.28 & $14.03^{\mathrm{a}}$ & \pm 0.53 \\
\hline \multicolumn{11}{|l|}{ Black tea } \\
\hline Gallic acid (GA) & $9.25^{\mathrm{a}}$ & \pm 0.09 & $9.14^{\mathrm{a}}$ & \pm 0.50 & $9.08^{a}$ & \pm 0.17 & $9.17^{\mathrm{a}}$ & \pm 0.28 & $9.32^{\mathrm{a}}$ & \pm 0.09 \\
\hline Epicatechin (EC) & $0.86^{\mathrm{c}}$ & \pm 0.08 & $0.95^{\mathrm{c}}$ & \pm 0.09 & $0.97^{\mathrm{c}}$ & \pm 0.09 & $1.32^{\mathrm{b}}$ & \pm 0.05 & $2.31^{\mathrm{a}}$ & \pm 0.07 \\
\hline Epicatechin gallate (ECG) & $13.22^{\mathrm{b}}$ & \pm 1.82 & $16.08^{\mathrm{a}}$ & \pm 0.93 & $16.11^{\mathrm{a}}$ & \pm 0.57 & $15.46^{\mathrm{a}}$ & \pm 0.77 & $14.20^{\mathrm{ab}}$ & \pm 1.26 \\
\hline Epigallocatechin (EGC) & $43.97^{\mathrm{ab}}$ & \pm 3.53 & $47.31^{\mathrm{a}}$ & \pm 2.11 & $47.57^{\mathrm{a}}$ & \pm 0.55 & $40.00^{\mathrm{bc}}$ & \pm 1.85 & $35.65^{c}$ & \pm 1.53 \\
\hline Epigallocatechin gallate (EGCG) & $20.97^{\mathrm{b}}$ & \pm 2.52 & $25.69^{\mathrm{a}}$ & \pm 1.9 & $27.01^{\mathrm{a}}$ & \pm 1.33 & $28.16^{\mathrm{a}}$ & \pm 3.42 & $26.94^{\mathrm{a}}$ & \pm 1.61 \\
\hline Gallocatechin (GC) & $7.86^{\mathrm{a}}$ & \pm 0.14 & $7.31^{\mathrm{b}}$ & \pm 0.1 & $6.21^{\mathrm{c}}$ & \pm 0.83 & $5.87^{\mathrm{c}}$ & \pm 0.23 & $4.73^{\mathrm{d}}$ & \pm 0.43 \\
\hline Gallocatechin gallate (GCG) & $1.05^{\mathrm{b}}$ & \pm 0.31 & $1.66^{\mathrm{a}}$ & \pm 0.28 & $1.91^{\mathrm{a}}$ & \pm 0.07 & $2.04^{\mathrm{a}}$ & \pm 0.29 & $1.90^{\mathrm{a}}$ & \pm 0.19 \\
\hline
\end{tabular}

For each compound, the significant differences in the content of a compound with time were indicated by various superscript letters $(\mathrm{p}<0.05)$

increase of polyphenol equilibrium concentration $\left(C_{e}\right)$ values (calculated from Eq. (6)). The $C_{e}$ values obtained for TPC were higher for green than for black tea (the $K_{2}$ values for green tea were lower than for black tea).

In case of logarithmic model the same trend was observed that for the previous ones; the extraction rate of total polyphenols from tea increased by increasing temperature.
The antioxidant activity of tea, expressed in the TEAC values, was also analyzed using the three selected models. Based on Spiro's model, the rate of the antioxidant activity (k) significantly increased with an increase of temperature (Table 4). Interestingly, $k$ values for black tea, which represent the Spiro's rate constant, were lower than the corresponding $k$ values for green tea. This indicates that 

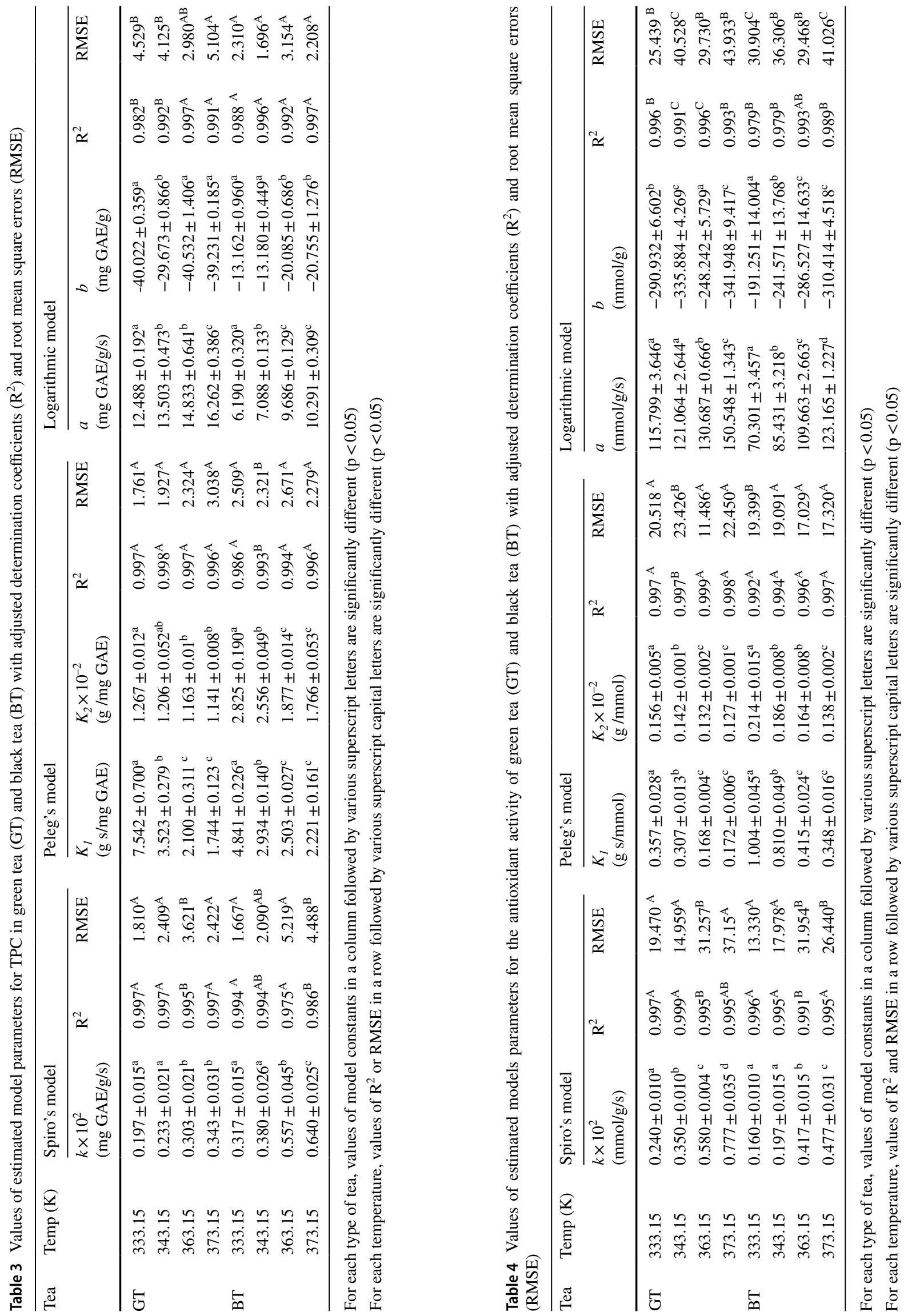
the reaction of catechins extracted from green tea with the $\mathrm{DPPH}^{\bullet}$ radicals is faster than the reaction of the bioactive compounds extracted from black tea. It may be due to the fact that during production of black tea more complex antioxidant active compounds are formed (theaflavins and thearubigins); the access of the $\mathrm{DPPH}^{\bullet}$ radicals to their reactive hydroxyl groups could be more difficult (due to steric hindrance).

On the basis of Peleg's model, the $K_{l}$ constant (Table 4) decreased with increasing temperature indicating that the antioxidant activity of tea at the beginning of the process was accelerated with temperature $\left(R_{0}\right.$ calculated from $K_{1}$ (Eq. 5) was from $2.80 \mathrm{mmol} / \mathrm{g} / \mathrm{s}$ to $5.81 \mathrm{mmol} / \mathrm{g} / \mathrm{s}$ for green tea, and from $0.99 \mathrm{mmol} / \mathrm{g} / \mathrm{s}$ to $2.87 \mathrm{mmol} / \mathrm{g} / \mathrm{s}$ for black tea). The $K_{2}$ values calculated for the TEAC values also decreased with higher temperature which indicated the temperature-dependent increase of antioxidant equilibrium concentration $\left(C_{e}\right)$ values (calculated from Eq. (6)). The $C_{e}$ values obtained for the TEAC values were higher for green than for black tea (the $K_{2}$ values for green tea were lower than for black tea).

For logarithmic model the same trend was observed that for the previous ones; the extraction rate of antioxidant active compounds from tea increased with an increase of temperature.

The effect of temperature was included to the mathematical models using Arrhenius relationship (Eq. 8). Based on the modified logistic Arrhenius equation (Eq. 9), the plot of $\ln k$ (for Spiro's model), $\ln \left(1 / K_{l}\right.$ ) (for Peleg's model) or $\ln a$ (for Logarithmic model) versus $1 / T$ gave straight regression lines for both teas with the slopes $-E a / R$ and $k_{0}$ as intercepts (Fig. 3). The temperature dependence of the extraction rates of phenolics was described by Arrhenius kinetics in the whole temperature range under study. From the slope of these regression lines $E_{a}$ values were calculated (Table 5).

$E_{a}$ values for polyphenol extraction from green tea were lower than for black tea based on the calculation from Spiro's (respectively, $14.239 \mathrm{~kJ} / \mathrm{mol}$ and $18.494 \mathrm{~kJ} / \mathrm{mol}$ ) and logarithmic models (respectively, $6.945 \mathrm{~kJ} / \mathrm{mol}$ and $13.770 \mathrm{~kJ} /$ $\mathrm{mol})$. The results imply that the polyphenol extraction rates for green tea calculated from the two models are less sensitive to temperature than the ones for black tea. However, based on the results obtained from Peleg's model, $E_{a}$ value calculated for the initial extraction rate $\left(R_{0}\right)$ of polyphenols from green tea was $35.622 \mathrm{~kJ} / \mathrm{mol}$ and was higher than $E_{a}$ $\left(R_{0}\right)$ obtained for black tea $(17.916 \mathrm{~kJ} / \mathrm{mol})$. Thus, it could be stated that the temperature affects the initial extraction rate of polyphenols from green tea more than that from black tea. Since $C_{e}$ calculated from the reciprocal of Peleg's $K_{2}$ constant (Eq. (6)) was also temperature-dependent, Arrhenius equation in its modified form (Eq. (10)) was used to calculate $E_{a}\left(C_{e}\right)$ (Tables 3 and 4). The $E_{a}\left(C_{e}\right)$ values for TPC in green tea were lower than in black tea. These results implied that $C_{e}$ tends to be more temperature sensitive for black tea rather than for green tea.

The $E_{a}$ values for the TEAC values of green tea were lower than those of black tea according to all three models included in the study (Table 5). Thus, the effect of temperature is more significant for the antioxidant activity changes of black than of green tea.

Since the phenolic content and the antioxidant activity of tea corresponds to the quality of tea infusions, these parameters could be used to create models predicting the quality changes of tea infusion in the function of time and temperature of infusion.

With the constant rates of empirical models (Tables 3 and 4) and the parameters calculated from Arrhenius equation (Table 5) the predictive models for tea quality (expressed as TPC and the TEAC values) were created based on the (Eqs. 2, 4 and 7). The validation of the models was performed by the comparison of the experimental data of the samples brewed at $80{ }^{\circ} \mathrm{C}$ with the predictive values calculated from the three models (Fig. 4) and $R^{2}, R M S E$ and $r$ were calculated to verify the model accuracy (Table 6). Based on the data from Fig. $4 a, b$ and Table 6 it could be concluded that Spiro's model gives very good prediction of the quality changes of green tea infusion (both, for TPC and TEAC parameters). The $R^{2}$ and $r$ values were the highest, and $R M S E$ values were the lowest. The coefficient of variation $(C V)$ for RMSE is below $10 \%$ for the model, with $C V$ equal to $6.64 \%$ and $5.45 \%$ for the prediction of TPC and the TEAC values, respectively. The following equations were created for green tea:

$\operatorname{TPCGT}(t)=C_{\infty}-C_{\infty} / \exp (k \times t)$, where

$k=0.340 \times \exp (-14239 /(R \times T))$

$\operatorname{TEACGT}(t)=C_{\infty}-C_{\infty} / \exp (k \times t)$, where

$k=104.954 \times \exp (-20515 /(R \times T))$

The TPC and the TEAC values of black tea could be accurately predicted by Peleg's model (Fig. 4c, d), with $C V$ values of $6.1 \%$ and $10.99 \%$ respectively for TPC and TEAC parameters (Table 6). The following equations were created for black tea:

$\operatorname{TPCBT}(t)=t /\left(K_{1}+K_{2} \times t\right)$, where

$K_{1}=1 /(153.659 \times \exp (-17916 /(R \times T)))$ and

$K_{2}=1 /(3813.568 \times \exp (-12891 /(R \times T)))$,

$\operatorname{TEACBT}(t)=t /\left(K_{1}+K_{2} \times t\right)$, where

$K_{1}=1 /(32591.986 \times \exp (-28835 /(R \times T)))$ and

$K_{2}=1 /(20245.501 \times \exp (-10287 /(R \times T)))$

The worst among mathematical models for the prediction of tea quality in the function of time and temperature of brewing was the logarithmic model (Table 6). 
TPC
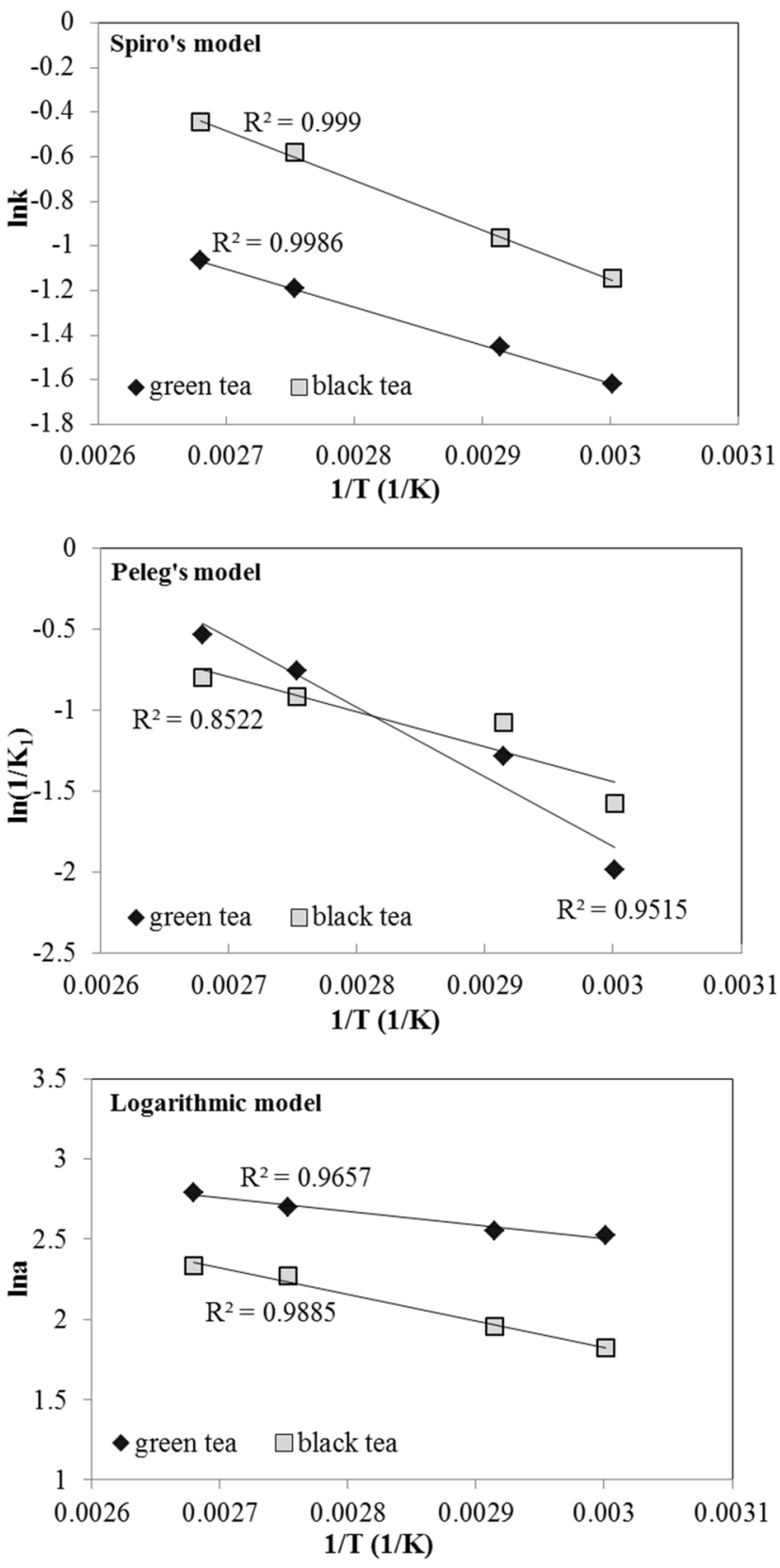

TEAC
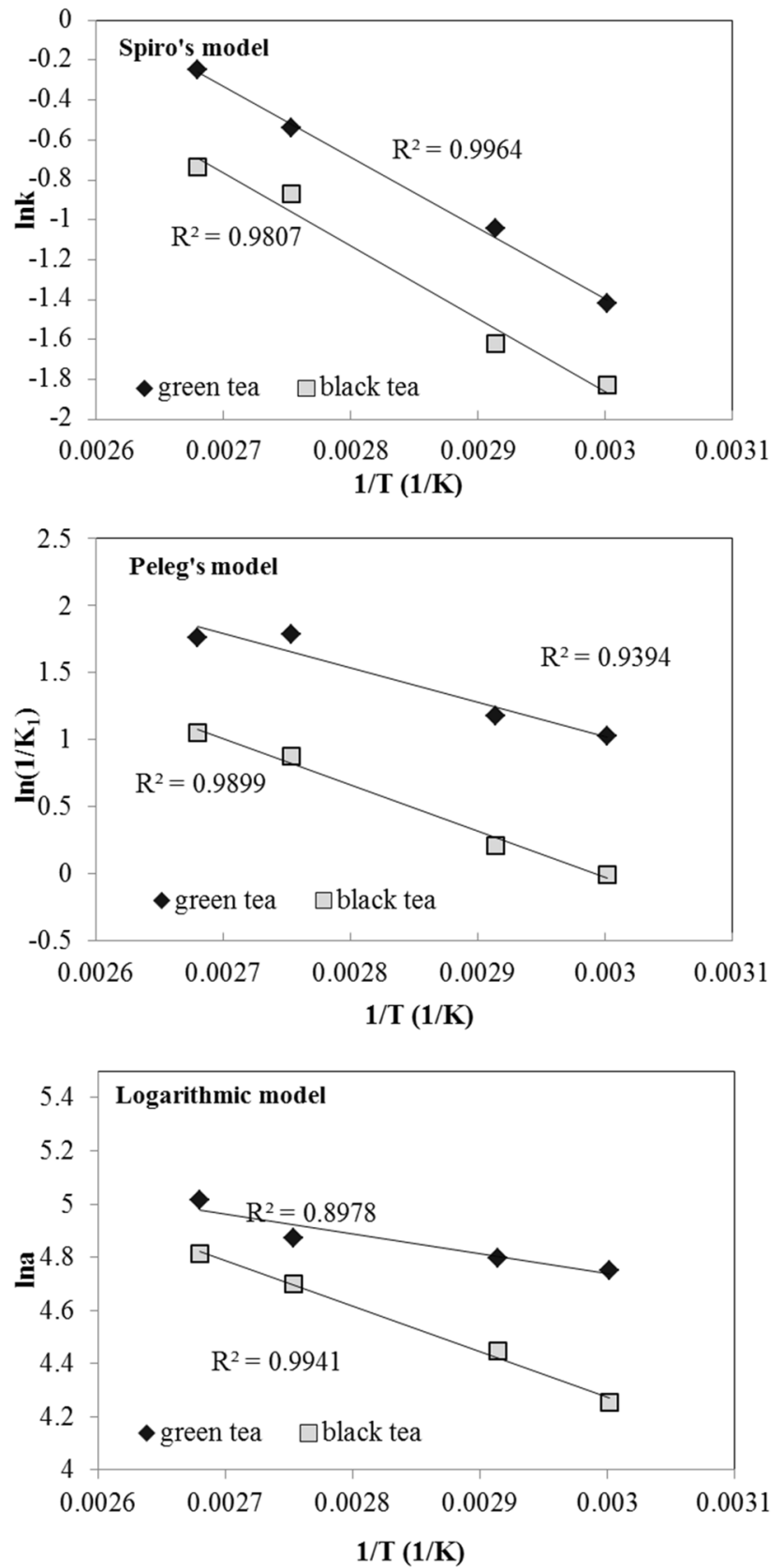

Fig. 3 Modeling temperature dependency of constant rates ( $k$ for Spiro's model, $K_{l}$ for Peleg's model and $a$ for logarithmic model) of total polyphenol content (TPC) and the antioxidant activity (TEAC) of green and black teas for the modified logistic Arrhenius equation

\section{Multivariate adaptive regression splines models}

The second order MARS model has been used in this study and the maximum number of terms was limited by pruning. The results of MARS models calculated by the Statistica program were shown in Table 7. The model created for TPC of green and black teas included, respectively, five and six terms as well as five and six basis functions. All predictor variables; time and temperature, were statistically significant. The $R^{2}$ values for TPC of green and black tea were equal to, respectively, 0.95 and 0.96 , whereas adjusted $R^{2}$ was 0.95 for both types of teas. The GCV calculated for TPC of green tea was 32.44 and of black tea 11.20. In Fig. 5a, c, the validation of the MARS models was shown by the comparison of the experimental data of the teas brewed at $80{ }^{\circ} \mathrm{C}$ with the predictive TPC values calculated from the MARS models (Table 7) and $R^{2}, R M S E$ and $r$ were calculated to verify the model 
Table 5 Activation energies $\left(E_{a}\right)$ and pre-exponential factors $\left(k_{0}\right)$ calculated, based on the Arrhenius equation, for the extraction of bioactive compounds (TPC) from green tea (GT) and black tea (BT) and their antioxidant activity (TEAC)

\begin{tabular}{|c|c|c|c|c|c|c|}
\hline & Spiro's model & Peleg's model & Logarithmic model & Spiro's model & Peleg's model & Logarithmic model \\
\hline Tea & \multicolumn{3}{|l|}{$E a(\mathrm{~kJ} / \mathrm{mol})$ for TPC } & \multicolumn{3}{|c|}{$E a(\mathrm{~kJ} / \mathrm{mol})$ for TEAC } \\
\hline GT & $14.239 \pm 0.0212$ & $\begin{array}{l}35.622 \pm 0.547\left(R_{0}\right) \\
2.706 \pm 0.114\left(C_{e}\right)\end{array}$ & $\begin{array}{l}6.945 \pm 0.532(a) \\
\text { n.l.r. }(b)\end{array}$ & $20.515 \pm 0.097$ & $\begin{array}{l}21.374 \pm 1.278\left(R_{0}\right) \\
5.069 \pm 0.564\left(C_{e}\right)\end{array}$ & $\begin{array}{l}6.419 \pm 0.450(a) \\
\text { n.1.r }(b)\end{array}$ \\
\hline \multirow[t]{2}{*}{ BT } & $18.494 \pm 0.084$ & $\begin{array}{l}17.916 \pm 0.442\left(R_{0}\right) \\
12.891 \pm 1.033\left(C_{e}\right)\end{array}$ & $\begin{array}{l}13.770 \pm 0.601(a) \\
14.123 \pm 0.134(b)\end{array}$ & $30.348 \pm 0.539$ & $\begin{array}{l}28.835 \pm 0.464\left(R_{0}\right) \\
10.287 \pm 1.136\left(C_{e}\right)\end{array}$ & $\begin{array}{l}14.217 \pm 0.975(a) \\
11.872 \pm 1.278(b)\end{array}$ \\
\hline & \multicolumn{3}{|c|}{$k_{0}(\mathrm{mg} \mathrm{GAE} / \mathrm{g} / \mathrm{s})$ for TPC } & \multicolumn{3}{|c|}{$k_{0}(\mathrm{mmol} / \mathrm{g} / \mathrm{s})$ for TEAC } \\
\hline GT & $0.340 \pm 0.030$ & $\begin{array}{l}62,599.608 \pm 1677.0 \\
\left(R_{0}\right) \\
210.436 \pm 6.129\left(C_{e}\right)\end{array}$ & $\begin{array}{l}152.221 \pm 32.092(a) \\
\text { n.l.r. }(b)\end{array}$ & $104.954 \pm 3.092$ & $\begin{array}{l}6652.359 \pm 303.609 \\
\left(R_{0}\right) \\
4109.359 \pm 72.057 \\
\left(C_{e}\right)\end{array}$ & $\begin{array}{l}1211.365 \pm 171.808 \\
\quad(a) \\
\text { n.l.r }(b)\end{array}$ \\
\hline BT & $2.514 \pm 0.539$ & $\begin{array}{l}153.659 \pm 26.111 \\
\left(R_{0}\right) \\
3813.568 \pm 111.778 \\
\left(C_{e}\right)\end{array}$ & $\begin{array}{l}904.588 \pm 155.919 \\
\quad(a) \\
1963.748 \pm 195.669 \\
\quad(b)\end{array}$ & $89.381 \pm 12.606$ & $\begin{array}{l}32,591.986 \pm 542.302 \\
\left(R_{0}\right) \\
20,245.501 \pm 76.088 \\
\left(C_{e}\right)\end{array}$ & $\begin{array}{l}12,535.849 \pm 364.517 \\
\quad(a) \\
15,306.531 \pm 562.696 \\
\quad(b)\end{array}$ \\
\hline
\end{tabular}

n.l.r not linear relationship
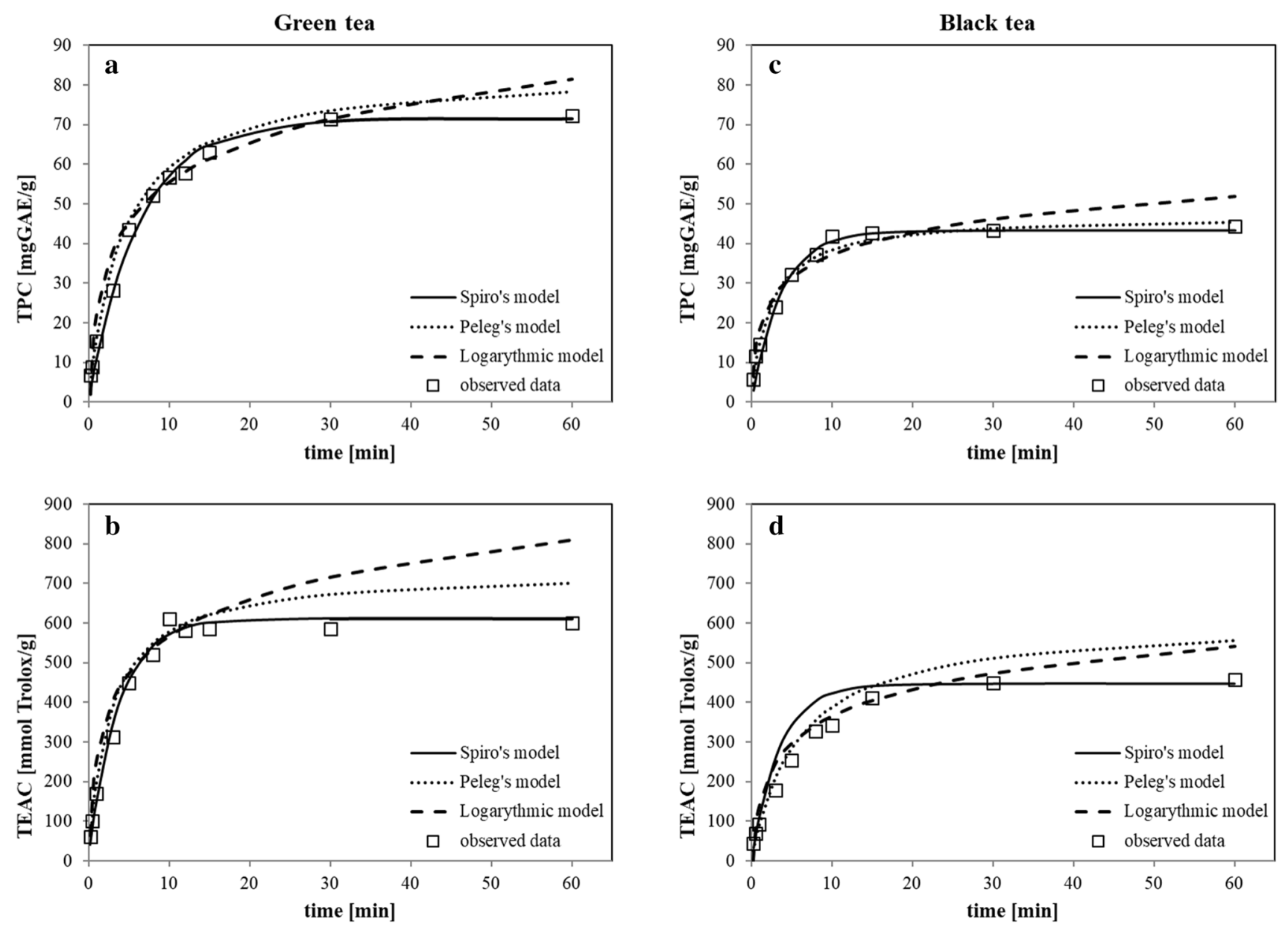

Fig. 4 The validation of the models generated for total polyphenol content (TPC) (a and b) and the antioxidant activity (expressed in the TEAC values) (c and d) of green and black teas brewed at $80{ }^{\circ} \mathrm{C}$ 
Table 6 Validation of generated models for TPC and TEAC values of green (GT) and black (BT) teas brewed at $80{ }^{\circ} \mathrm{C}$

\begin{tabular}{|c|c|c|c|c|c|c|c|}
\hline \multirow[b]{2}{*}{ Tea } & & \multicolumn{3}{|l|}{ ТPC } & \multicolumn{3}{|l|}{ TEAC } \\
\hline & & Spiro's model & Peleg's model & $\begin{array}{l}\text { Logarith- } \\
\text { mic model }\end{array}$ & Spiro's model & Peleg's model & $\begin{array}{l}\text { Loga- } \\
\text { rithmic } \\
\text { model }\end{array}$ \\
\hline \multirow[t]{3}{*}{ GT } & $\mathrm{R}^{2}$ & 0.996 & 0.994 & 0.990 & 0.997 & 0.990 & 0.968 \\
\hline & $\mathrm{r}$ & 0.998 & 0.994 & 0.979 & 0.996 & 0.986 & 0.953 \\
\hline & RMSE & 2.779 & 3.746 & 4.739 & 22.691 & 44.083 & 83.109 \\
\hline \multirow[t]{3}{*}{ BT } & $\mathrm{R}^{2}$ & 0.993 & 0.997 & 0.989 & 0.968 & 0.991 & 0.975 \\
\hline & $\mathrm{r}$ & 0.995 & 0.992 & 0.971 & 0.968 & 0.996 & 0.980 \\
\hline & RMSE & 2.565 & 1.814 & 3.382 & 53.548 & 28.824 & 40.605 \\
\hline
\end{tabular}

Table 7 MARS model coefficients and basis functions calculated for TPC and the TEAC values of green (GT) and black (BT) teas

\begin{tabular}{|c|c|c|c|c|c|}
\hline \multirow[b]{2}{*}{ Tea } & \multirow[b]{2}{*}{$\begin{array}{l}\text { Number of } \\
\text { term }\end{array}$} & \multicolumn{2}{|l|}{ TPC } & \multicolumn{2}{|l|}{ TEAC } \\
\hline & & Coefficients $(\beta)$ & Basis functions $(h)$ & Coefficients $(\beta)$ & Basis functions $(h)$ \\
\hline \multirow[t]{5}{*}{ GT } & 1 & 40.37 & 1 & 451.19 & 1 \\
\hline & 2 & $6.23 \times 10^{-3}$ & $\max (0$, time -300$)$ & $3.79 \times 10^{-2}$ & $\max (0$, time -300$)$ \\
\hline & 3 & $-1.30 \times 10^{-1}$ & $\max (0,300$-time $)$ & -1.34 & $\max (0,300$-time $)$ \\
\hline & 4 & $6.00 \times 10^{-1}$ & $\max (0$, temp-60) & 3.78 & $\max (0$, temp-60) \\
\hline & 5 & $-1.21 \times 10^{-3}$ & $\max (0$, temp-60) $\times \max (0,300$-time $)$ & $-8.44 \times 10^{-3}$ & $\max (0$, temp- -60$) \times \max (0,300$-time $)$ \\
\hline \multirow[t]{8}{*}{ BT } & 1 & 48.85 & 1 & 477.72 & 1 \\
\hline & 2 & $7.66 \times 10^{-4}$ & $\max (0$, time-600$)$ & $1.63 \times 10^{-2}$ & $\max (0$, time-600$)$ \\
\hline & 3 & $6.16 \times 10^{-2}$ & $\max (0,600$-time $)$ & $-6.74 \times 10^{-1}$ & $\max (0,600$-time $)$ \\
\hline & 4 & $2.66 \times 10^{-1}$ & $\max (0$, temp-90) & 7.65 & $\max (0$, temp-90) \\
\hline & 5 & $-6.02 \times 10^{-1}$ & $\max (0,90$-temp $)$ & -6.63 & $\max (0,90-$ temp $)$ \\
\hline & 6 & $8.05 \times 10^{-4}$ & $\max (0,90$-temp $) \times \max (0,600$-time $)$ & $9.46 \times 10^{-4}$ & $\max (0,90-$ temp $) \times \max (0$, time-600$)$ \\
\hline & 7 & - & - & $9.37 \times 10^{-3}$ & $\max (0,90$-temp $) \times \max (0,600$-time $)$ \\
\hline & 8 & - & - & $-8.46 \times 10^{-3}$ & $\max (0$, temp- -90$) \times \max (0,600$-time $)$ \\
\hline
\end{tabular}

accuracy. Obtained models predicted the data very good, since the determination and correlation coefficients were high $\left(R^{2}=0.99, \mathrm{r}=0.98\right.$ for both types of tea), whereas $R M S E$ values low $(R M S E=5.0$ for green tea and 2.8 for black tea). The $C V$ values were around $10 \%$ (9.4\% for black tea and $11.5 \%$ for green tea).

The MARS models created for the prediction of the antioxidant activity changes of green and black teas were also presented in Table 7. For the TEAC values of green tea five terms and five basis functions were included in the model whereas the antioxidant activity of black tea could be described by the MARS model contained eight terms and eight basis functions. The goodness of fit of both models was very high. The adjusted $R^{2}$ values were equal to 0.96 and 0.97 for green and black teas, respectively. To verify the model accuracy, the comparison of the experimental data of the teas brewed at $80{ }^{\circ} \mathrm{C}$ with the predictive TEAC values calculated from the MARS models was shown on Fig. 5b, $\mathrm{d}$ and $R^{2} R M S E$, and $r$ values were calculated. The MARS models obtained showed very high accuracy, since $R^{2}$ was equal to 0.99 for both types of teas and $r=0.98$ for green tea and $r=0.99$ for black tea, whereas $\mathrm{RMSE}=42.0$ for green tea and 27.3 for black tea. The $\mathrm{CV}$ values were equal to $10.09 \%$ for green tea and $10.42 \%$ for black tea.

\section{Artificial neural network models}

The prediction of tea quality based on TPC and the TEAC values was performed with an artificial neural networks. The best five ANN-MLP networks are presented in Tables 8 and 9. In the neural network obtained for TPC of green tea (Table 8), the logistic and exponential functions were used in the hidden layer, whereas the logistic, identity and Tanh functions were used in the output layer. For the TPC in black tea, the hidden layer was based on Tanh and logistic functions, while the output layer Tanh-on identity and 

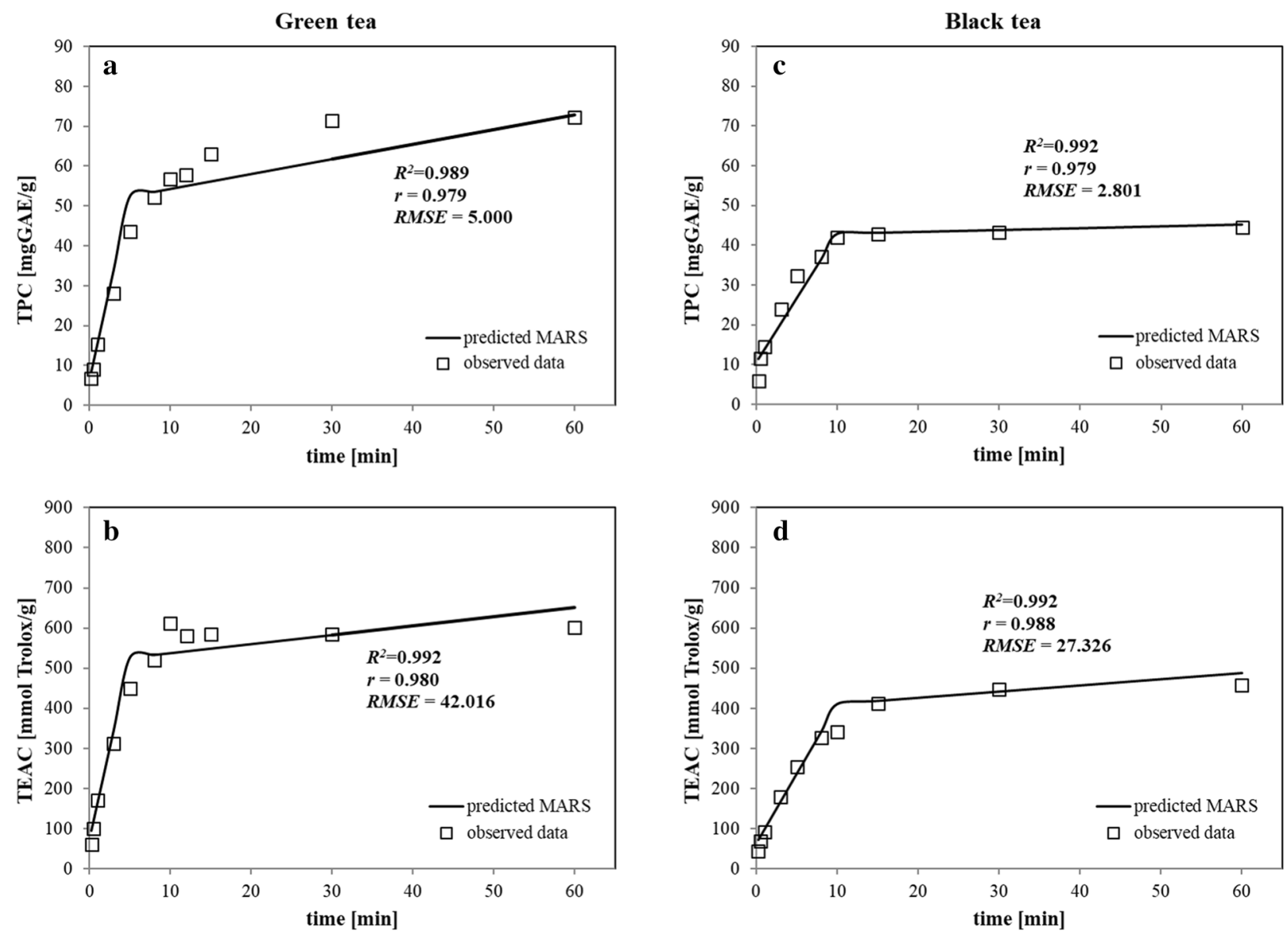

Fig. 5 The validation of the MARS models generated for total polyphenol content (TPC) (a and $\mathbf{b}$ ) and the antioxidant activity (expressed in the TEAC values) (c and d) of green and black teas brewed at $80{ }^{\circ} \mathrm{C}$

exponential functions. For the TEAC values analysis by the ANN method mainly exponential and also logistic functions were used in the input and output layers (Table 9). The accuracy of the models to predict TPC and TEAC was very high and accounted for more than 0.99 for the training, test and validation sets of data. The accuracies of the models obtained could be also expressed as the sum of square error values, as presented in Tables 8 and 9. The values indicated satisfactory quality of the presented ANN models.

\section{Conclusions}

The content of phenolics is highly correlated with the antioxidant activity of tea, and could be used as a quality parameter of tea. Thus, for the first time, the predictive models were developed for the description of the quality changes of green and black tea infusions under various time and temperature conditions. Most of the tea bioactive compounds were extracted from the samples during $30 \mathrm{~min}$ of the extraction process. The highest values of TPC and TEAC were achieved at the highest temperature of $100{ }^{\circ} \mathrm{C}$ for both teas.

The experimental data of TPC and TEAC values were fitted to three mathematical models: Spiro's, Peleg's and Logarithmic models as well as implemented to MARS and ANN models. This study demonstrated the high potential of the selected models for the prediction of tea quality during infusion, providing reliable results and models of simple application. Moreover, data mining techniques (MARS and ANNs) enable to create models very fast using the high number of data. The results presented here together with the models built could be developed further to fully validate the effectiveness of all models, using a higher number of green and black tea samples. 

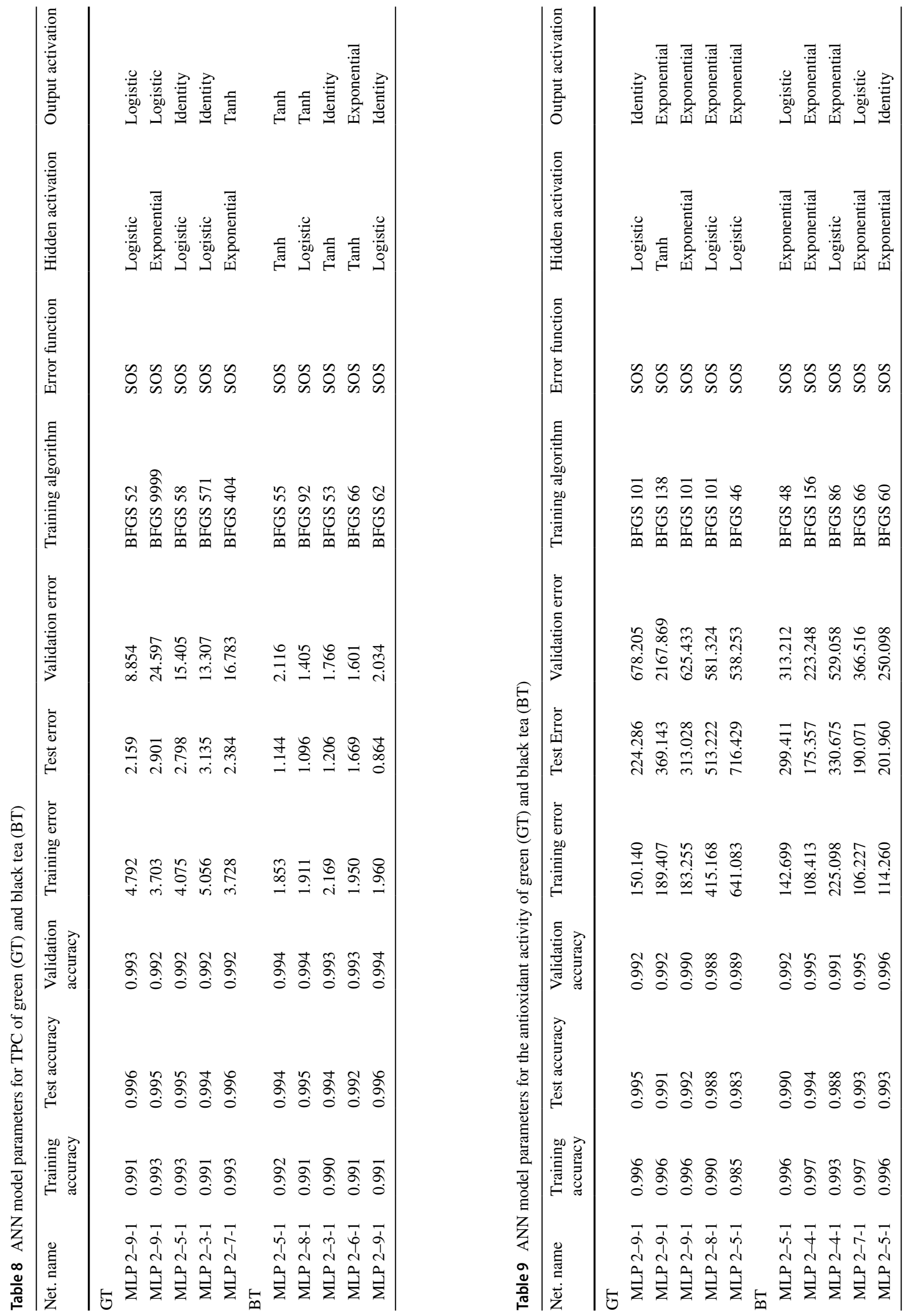


\section{Compliance with ethical standards}

Conflict of interest The authors declare that they have no conflict of interest.

Research involving human and animals studies The manuscript does not contain experiments using animals or human studies.

Open Access This article is licensed under a Creative Commons Attribution 4.0 International License, which permits use, sharing, adaptation, distribution and reproduction in any medium or format, as long as you give appropriate credit to the original author(s) and the source, provide a link to the Creative Commons licence, and indicate if changes were made. The images or other third party material in this article are included in the article's Creative Commons licence, unless indicated otherwise in a credit line to the material. If material is not included in the article's Creative Commons licence and your intended use is not permitted by statutory regulation or exceeds the permitted use, you will need to obtain permission directly from the copyright holder. To view a copy of this licence, visit http://creativecommons.org/licenses/by/4.0/.

\section{References}

1. M. Muzolf-Panek, A. Gliszczyńska-Świgło, H. Szymusiak, B. Tyrakowska, Eur. Food Res. Technol. 235, 1001 (2012)

2. M. Muzolf, H. Szymusiak, A. Gliszczyńska-Świgło, I.M.C.M. Rietjens, B. Tyrakowska, J. Agric. Food Chem. 56, 816 (2008)

3. S. Saklar, E. Ertas, I.S. Ozdemir, B. Karadeniz, J. Food Sci. Technol. 52, 6639 (2015)

4. C.D. Fernando, P. Soysa, Nutr. J. 14, 74 (2015)

5. R. Wang, W. Zhou, X. Jiang, J. Agric. Food Chem. 56, 2694 (2008)

6. J. Xi, L. He, L. Yan, Food Chem. 166, 287 (2015)

7. J. Xi, L. Yan, L. He, Sep. Purif. Technol. 133, 155 (2014)

8. D. Jaganyi, R.D. Price, Food Chem. 64, 27 (1999)

9. M.A.J.S. Van Boekel, Compr. Rev. Food Sci. Food Saf. 7, 144 (2008)

10. S. Kitanović, D. Milenović, V. Veljkvić, Biochem. Eng. J. 41, 1 (2008)

11. D. Jaganyi, P.J. Wheeler, Food Chem. 83, 121 (2003)

12. W. Price, J. Spitzer, Food Chem. 47, 271 (1993)

13. M. Spiro, D.S. Jago, J. Chem. Soc. Faraday Trans. 1(78), 295 (1982)
14. S. Jokic, D. Velic, M. Bilic, Ana Bucic-Kojic, M. Planinic, S. Tomasa, Czech J. Food Sci. 28, 206 (2010)

15. A. Jurinjak Tušek, M. Benković, A. Belščak Cvitanović, D. Valinger, T. Jurina, J. Gajdoš Kljusurić, Ind. Crops Prod. 91, 205 (2016)

16. M. Peleg, J. Food Sci. 53, 1216 (1988)

17. A. Bucić-Kojić, M. Planinić, S. Tomas, M. Bilić, D. Velić, J. Food Eng. 81, 236 (2007)

18. M.C. Wei, Y.C. Yang, Sep. Purif. Technol. 142, 316 (2015)

19. G. Spigno, D.M. De Faveri, J. Food Eng. 93, 210 (2009)

20. Statsoft, https://www.statsoft.com/textbook/multivariate-adapt ive-regression-splines, (n.d.).

21. I. Uysal, H.A. Güvenir, Knowl. Eng. Rev. 14, 319 (1999)

22. L.A. Berrueta, R.M. Alonso-Salces, K. Héberger, J. Chromatogr. A 1158, 196 (2007)

23. C. Sánchez-Moreno, J.A. Larrauri, F. Saura-Calixto, J. Sci. Food Agric. 76, 270 (1998)

24. M. Muzolf-Panek, A. Waśkiewicz, R. Kowalski, P. Konieczny, J. Food Process. Preserv. 40, 899 (2016)

25. V.L. Singleton, J.A. Rossi, Am. J. Enol. Vitic. 16, 144 (1965)

26. J. Enko, A. Gliszczyńska-Świgło, Food Addit. Contam. Part A 32, $1234(2015)$

27. M. Muzolf, A. Gliszczyńska-Świgło, B. Tyrakowska, Polish J. Nat. Sci. Suppl. 04, 63 (2007)

28. A. Gramza, S. Khokhar, S. Yoko, A. Gliszczynska-Swiglo, M. Hes, J. Korczak, Eur. J. Lipid Sci. Technol. 108, 351 (2006)

29. F. Hajiaghaalipour, J. Sanusi, M.S. Kanthimathi, J. Food Sci. 81, H246 (2016)

30. D. Komes, D. Horžić, A. Belščak, K.K. Ganić, I. Vulić, Food Res. Int. 43, 167 (2010)

31. G. Rusak, D. Komes, S. Likić, D. Horžić, M. Kovač, Food Chem. 110, 852 (2008)

32. P. Carloni, L. Tiano, L. Padella, T. Bacchetti, C. Customu, A. Kay, E. Damiani, Food Res. Int. 53, 900 (2013)

33. M. Torun, C. Dincer, A. Topuz, H. Sahin-Nadeem, F. Ozdemir, J. Food Sci. Technol. 52, 2797 (2015)

34. E. Karacabey, L. Bayindirli, N. Artik, G. Mazza, J. Food Process Eng. 36, 103 (2013)

35. A.R. Linares, S.L. Hase, M.L. Vergara, S.L. Resnik, J. Food Eng. 97, 471 (2010)

Publisher's Note Springer Nature remains neutral with regard to jurisdictional claims in published maps and institutional affiliations. 